\title{
Rediscovery of hearing disorders with normal audiometry or hidden deafness
}

\author{
Gersdorff G, De Siati RD, Grégoire A, Huart C and Deggouj N* \\ UCLouvain, Institute of Neuroscience IoNS, academic hospital Saint-Luc Brussels - ORL-HNS department, Belgium
}

Some subjects present isolated hearing disorders for speech discrimination in difficult auditory conditions with normal tonal and speech audiometry in quiet and normally synchronized auditory brainstem responses (ABR). They have a preserved audibility but degraded intelligibility. The prevalence of this hidden deafness is reported between 5 and 15\% [1].

Many synonyms and confusions are related to this set of hearing dysfunctions: "Hidden deafness", "auditory processing disorders (APD)", "supraliminal hearing disorders", "auditory synaptopathy" or even "Central" hearing disorders. Notably, this latter definition is not correct because the exact origin is unknown and may be localized wherever from the outer hair cells (OHC) to top of auditory pathway, involved in cognition-related mechanisms of auditory perception. Indeed, an abnormal peripheral cochlear coding of sound features (spectral, intensity, temporal) could be responsible of APD. This peripheral dys-coding will be more or less reprinted at the upper levels of the auditory pathways. It seems clear that not all APD have a central origin and that the notion of "central" auditory processing disorders should be reviewed [2].

There are still many confusions between peripheral and central APD as well as between APD and auditory neuropathy spectrum disorders (ANSD). ANSD subjects present also a degradation of speech intelligibility. However, unlike APD, ABR in ANSD show abnormal wave $\mathrm{V}$ with preserved cochlear microphonic and/or otoacoustic emissions (OAE). If diffuse cochlear synaptopathy or auditory neuropathy may produce ANSD, APD may result from limited dysfunction at any level of the auditory system [3].

Only the three possible peripheral origins of APD are discussed below OHC, inner hair cells (IHC) and synapses-cochlear neural fibers [4]. Partial OHC loss may show no impact on hearing perception and be undetectable on audiometry tests performed at low intensities and in quiet. The hearing thresholds may remain normal with a third of $\mathrm{OHC}$ loss ( $3^{\text {rd }}$ raw loss). However, this loss may affect the supraliminal auditory processing of speech, especially in difficult auditory conditions. It is also suspected to increase the sensitivity to ototoxicity (e.g. to noise or age) [5]. Acute partial IHC loss in animal models leads to a decrease in cochlear output and an increase in the hearing thresholds [6]. However, up to $80 \%$ IHC loss, the threshold shift may be less than $5 \mathrm{~dB}$ [7]. It is possible to have normal tonal audiometry thanks to an enhancement of the central auditory gain. A selective synaptopathy of the neural fibers, showing high responses thresholds and spontaneous low discharge, can lead to decreased cochlear output for high intensities but preserved hearing thresholds [4]. The origins of this synaptopathy are unclear: age, noise, genetic factors and other ototoxics like cisplatin have been suggested [8]. Synaptopathy may appear before the loss of IHC and may likely be related to at least some of hearing difficulties experienced in noisy environments despite normal or near normal hearing acuity [9-12].

Various psychoacoustic tests are used for the assessment of hidden deafness. Standard tonal audiometry must be completed by extending the thresholds research to higher than $8 \mathrm{kHz}$ frequencies or to frequency bands lower than 1 octave band [4,13]. Speech audiometry in noise remains a gold standard supraliminal test to diagnose this disorder [14]. Various supraliminal auditory tests, that have been used in the past, were supposed to mainly investigate the central auditory processing. It is now clear that this processing extends from the peripheral to the central audition. For instance, the so-called "Central" auditory battery (CAB) of Demanez is frequently abnormal. This test has been conceived to detect poor phonemic discrimination in quiet and in noise, abnormal dichotic and demasking abilities, limited detection of changes in frequencies, intensities or duration patterns [15-17]. Individuals with APD have less ability to detect spectral and temporal features, which may be evaluated by various temporal and localization tests.

Otoacoustic emissions (OAE) are abnormal in case of OHC lesions [18]. Distortion Products are more sensitive to detect $\mathrm{OHC}$ dysfunctions than extended high frequencies audiograms [4]. The contralateral median olivocochlear inhibition (Collet's effect) is impaired in APD subjects showing no decrease of their OAE amplitude in presence of contralateral noise $[19,20]$.

Many electrophysiological tests have been used for the investigation of this set of disorders, however, their real clinical usefulness is still in discussion [21]. For instance, a decreased wave I but a betterpreserved wave $\mathrm{V}$ amplitude have been reported on ABR [22-25]. Increased ratio of SP (summating potential) /AP (action potential) on electrocochleography may be a sign of auditory neural fibers damage [26]. Speech ABR and frequency following responses may demonstrate damage to high threshold cochlear fibers with loss of the phase locking and therefore impairment in the coding of the envelope of sounds, especially in noise [27,28]. Abnormal cognitive and/or obligatory cortical auditory potentials may be disturbed in APD subjects [29].

The treatment of hidden deafness also remains very challenging. It is based on hearing training and connectivity use. The adaptation of

${ }^{\star}$ Correspondence to: Naima Deggouj, Cliniques Saint-Luc, 10 Avenue Hippocrate, 1200, Bruxelles, Belgium,E-mail: naima.deggouj@uclouvain.be

Key words: auditory processing disorders, auditory synaptopathy, central hearing disorders, hidden deafness, supraliminal hearing disorders, supra-liminal tests

Received: December 30, 2019; Accepted: January 10, 2020; Published: January 13,2020 
subjects to their disorders is improved by auditory training in quiet and in noise, as well as by increasing their audiovisual integration of speech in congruent and incongruent conditions, in order to benefit from all the useful cues for communication. It is possible to act on the environment and the subject / environment interaction by promoting an articulated and slower speech flow, a decrease in the noise and reverberation levels, a placement in front of the speakers for a better exposition to the speech signal and less to noise, and by encouraging visual aids use. Finally, the incoming signal may be improved by receiving the signal without noise by Frequency Modulation (FM) System.

\section{Conclusion}

In conclusion, it seems important to get away from the concept of a systematic central origin of auditory processing disorders, and to valorize the concept of possible peripheral auditory encoding disorders. A functional loss of the cochlea does not necessarily mean a loss of hearing sensitivity. Supra-liminal tests are probably not so obsolete that we thought. Their place in the current practice is re-discovered and increasing.

\section{Authors contribution}

GG and ND wrote the original manuscript followed by all coauthors commenting on the original manuscript and approved the final work.

\section{Conflicts of interest}

No conflicts of interest.

\section{References}

1. Davis AC (1989) The prevalence of hearing impairment and reported hearing disability among adults in Great Britain. Int J Epidemiol 18: 911-917.

2. Iliadou V, Ptok M, Grech H, Pedersen ER, Brechmann A, Deggouj N, et al. (2017) A European perspective on auditory processing disorder-current knowledge and future research focus. Front Neurol 8: 622.

3. Ehrmann-Muller D, Cebulla M, Rak K, Scheich M, Back D, Hagen R, et al. (2019) Evaluation and Therapy Outcome in Children with Auditory Neuropathy Spectrum Disorder (ANSD). Int J Pediatr Otorhinolaryngol 9: 127.

4. Chen GD (2018) Hidden cochlear impairments. Journal of Otology 13: 37-43.

5. Chen GD, Tanaka C, Henderson D (2008) Relation between outer hair cell loss and hearing loss in rats exposed to styrene. Hear Res 243: 28-34.

6. Bakay WM, Anderson LA, Garcia-Lazaro JA, McAlpine D, Schaette R, et al. (2018) hidden hearing loss selectively impairs neural adaptation to loud sound environments. Nature communications 9: 4298.

7. Lobarinas E, Salvi R, Ding D (2013) Insensitivity of the audiogram to carboplatin induced inner hair cell loss in chinchillas. Hear Res 302: 113e120.

8. Maison SF, Usubuchi H, Liberman MC (2013) Efferent feedback minimizes cochlear neuropathy from moderate noise exposure. $J$ Neurosci 33: 5542-5552.

9. Kujala T, Shtyrov Y, Winkler I (2004) Long-term exposure to noise impairs cortical sound processing and attention control. Psychophysiology 41: 875-881.
10. Brattico E, Kujala T, Tervaniemi M (2005) Long-term exposure to occupational noise alters the cortical organization of sound processing. Clin Neurophysiol 116: 190-203.

11. Humes LE, Dubno JR, Gordon-Salant S (2012) Central presbycusis: A review and evaluation of the evidence. J Am Acad Audiol 23: 635-666.

12. Füllgrabe C, Moore BC, Stone MA (2014) Age-group differences in speech identification despite matched audiometrically normal hearing: Contributions from auditory temporal processing and cognition. Front Aging Neurosci 6: 347.

13. Xiong B, Liu Z, Liu Q, Peng Y, Wu H, Lin Y, et al. (2019) Missed hearing loss in tinnitus patients with normal audiograms. Hearing Research 384: 107826.

14. Watson CS, Kidd GR (2009) Associations between auditory abilities, reading, and other language skills, in children and adults. In A. T. Cacace \& D. J. McFarland (Eds.) Current Controversies in Central Auditory Processing Disorder (CAPD). San Diego, CA: Plural Publishing, 2009.

15. Deggouj N, Giraudet F, Veuillet E, Thai-Van H (2018) Explorations in so-called central auditory processing (in French)]. In Rapport of the Société Française d'ORL et de chirurgie cervico-faciale, 2018, Truy E, Lescanne E, Loundon N, Roman S (eds). Paris, France: Edition Elsevier Masson 2018,

16. Ahmmed AU, Ahmmed AA, Bath JR, Ferguson MA, Plack CJ, Moore DR, et al. (2014) Assessment of children with suspected auditory processing disorder: a factor analysis study. Ear Hear 35: 295-305.

17. Deggouj N, Demanez L (2016) Maturation des processus auditifs centraux. Cahier de l'audition 23: 29-36.

18. Zhao F, Stephens D (2006) Distortion product otoacoustic emissions in patients with King-Kopetzky syndrome. Int J Audiol 45: 34-39.

19. Froud KE, Wong AC, Cederholm JM (2015) Type II spiral ganglion afferent neurons drive medial olivocochlear reflex suppression of the cochlear amplifier. Nat Commun 6: 7115 .

20. Veuillet E, Magnan A, Ecalle J, Thai-Van H, Collet L (2007) Auditory processing disorder in children with reading disabilities: effect of audiovisual training. Brain 130: 2915-28.

21. Pienkowski (2019) On the Etiology of Listening Difficulties in Noise Despite Clinically Normal Audiograms. Ear Hear 38: 135-148.

22. Turrigiano GG (1991) Homeostatic plasticity in neuronal networks: The more things change, the more they stay the same. Trends Neurosci 22: 221-227.

23. Salvi RJ, Wang J, Ding D (2000) Auditory plasticity and hyperactivity following cochlear damage. Hear Res 147: 261-274.

24. Schaette R, McAlpine D (2011) Tinnitus with a normal audiogram: physiologica evidence for hidden hearing loss and computational model. Soc Neurosci 31: 1345213457.

25. Chambers AR, Resnik J, Yuan Y (2016) Central gain restores auditory processing following near-complete cochlear denervation. Neuron 89: 867-879.

26. Epstein M, Cleveland S, Wang H (2016) Hidden hearing loss in young adults: audiometry, speech discrimination and electrophysiology. 39th Mid-winter Meeting of the Association for Research in Otolaryngology (San Diego, CA), PS 781.

27. Akhoun I, Moulin A, Jeanvoine A, Ménard M, Buret F, Vollaire C, et al. (2008) Speech auditory brainstem response (speech ABR) characteristics depending on recording conditions, and hearing status: An experimental parametric study. J Neurosci Methods 175: 196-205.

28. Aiken SJ, Picton TW (2008) Envelope and spectral frequency-following responses to vowel sounds. Hearing Research 245: 35-47.

29. Anderson S, Chandrasekaran B, Yi HG, Kraus N (2010) Cortical-evoked potentials reflect speech-in-noise perception in children. Eur J Neurosci 32: 1407-1413.

Copyright: (C2020 Gersdorff G. This is an open-access article distributed under the terms of the Creative Commons Attribution License, which permits unrestricted use, distribution, and reproduction in any medium, provided the original author and source are credited. 